\title{
The Alexander Technique and musicians: a systematic review of controlled trials
}

\author{
Sabine D Klein ${ }^{\dagger}$, Claudine Bayard ${ }^{\dagger}$ and Ursula Wolf ${ }^{*}$
}

\begin{abstract}
Background: Musculoskeletal disorders, stress and performance anxiety are common in musicians. Therefore, some use the Alexander Technique (AT), a psycho-physical method that helps to release unnecessary muscle tension and re-educates non-beneficial movement patterns through intentional inhibition of unwanted habitual behaviours. According to a recent review AT sessions may be effective for chronic back pain. This review aimed to evaluate the evidence for the effectiveness of AT sessions on musicians' performance, anxiety, respiratory function and posture.

Methods: The following electronic databases were searched up to February 2014 for relevant publications: PUBMED, Google Scholar, CINAHL, EMBASE, AMED, PsycINFO and RILM. The search criteria were "Alexander Technique" AND "music*". References were searched, and experts and societies of AT or musicians' medicine contacted for further publications.

Results: 237 citations were assessed. 12 studies were included for further analysis, 5 of which were randomised controlled trials (RCTs), 5 controlled but not randomised (CTs), and 2 mixed methods studies. Main outcome measures in RCTs and CTs were music performance, respiratory function, performance anxiety, body use and posture. Music performance was judged by external experts and found to be improved by AT in 1 of 3 RCTs; in 1 RCT comparing neurofeedback (NF) to AT, only NF caused improvements. Respiratory function was investigated in 2 RCTs, but not improved by AT training. Performance anxiety was mostly assessed by questionnaires and decreased by AT in 2 of 2 RCTs and in 2 of 2 CTs.

Conclusions: A variety of outcome measures has been used to investigate the effectiveness of AT sessions in musicians. Evidence from RCTs and CTs suggests that AT sessions may improve performance anxiety in musicians. Effects on music performance, respiratory function and posture yet remain inconclusive. Future trials with well-established study designs are warranted to further and more reliably explore the potential of AT in the interest of musicians.
\end{abstract}

Keywords: Alexander technique, Systematic review, Musician, Performance anxiety, Posture

\section{Background}

Music playing-related injuries, stress and performance anxiety are common in music students, professionals as well as amateur musicians. Most frequently reported are musculoskeletal disorders such as back and neck pain, inflammation of the tendon sheets, muscular overuse syndromes and neuropathy in the upper limbs, depending on the instrument played [1,2]. Systematic reviews found $39-87 \%$ [3] and 29-93\% [4] of playing-related musculoskeletal disorders in adult orchestral musicians and pianists,

\footnotetext{
* Correspondence: ursula.wolf@ikom.unibe.ch

${ }^{\dagger}$ Equal contributors

Institute of Complementary Medicine, University of Bern, $\mathrm{CH}-3010$ Bern, Switzerland
}

respectively. Although the wide prevalence range suggests a heterogeneous definition of disorders included in these studies, it becomes apparent that musculoskeletal disorders represent a major problem among instrumental musicians. Other known disorders in musicians include performance anxiety [5], focal dystonia [6], tinnitus [7], problems of the lips and teeth [8] as well as contact allergies [9].

Musculoskeletal disorders are commonly addressed with physical therapy, but specialised care for musicians is rarely available [10]. Hence, other methods such as Alexander Technique (AT), yoga or Feldenkrais method are also used. AT is a psychophysical method, developed by Frederick Matthias Alexander (1869-1955). It uses

\section{Biomed Central}


enhanced kinaesthetic awareness and voluntary inhibition to prevent non-beneficial movement patterns. The primary focus is put on the relationship between head, neck and back as crucial in effecting an overall integrated pattern of coordinated behaviour. Through this conscious re-education of thinking and moving unnecessary muscle tension is released, which leads to more ease in movement and breathing and a better coordinated "use" (technical AT term describing the manner in which a person moves and behaves). AT is usually taught one-to-one by licensed teachers and combines verbal instructions with hands-on guidance. The psychophysical connection through hands-on work is specific for AT and distinguishes it from bodywork techniques.

According to a recent review, there is good evidence that AT lessons are effective for chronic back pain [11]. Musicians report that AT enables them to move and breathe more easily and thereby improves their quality of music playing $[12,13]$, but effects of psychophysical therapies are generally not easy to assess objectively. Since AT may in principle constitute a promising method for musicians, an overview of published studies including outcome parameters used and limitations encountered would help to facilitate the design of future studies.

Therefore, the aim of this review was to evaluate systematically the current evidence for the effectiveness of AT sessions (one-to-one or group lessons) for musicians' health and improved music performance. Since little research on this topic was found searching scientific databases, a broader search strategy had to be used. Therefore, additionally to peer-reviewed articles, master's and doctoral theses as well as conference proceedings were included.

\section{Methods}

The preferred reporting items for systematic reviews and meta-analyses (PRISMA) guidelines were followed in this review [14]. The review was not registered in any database.

\section{Literature search}

The following electronic databases were searched for relevant publications: PUBMED, CINAHL, EMBASE, AMED, PsycINFO, RILM and Google Scholar. The publication time was from the start of each database up to February 2014. The search criteria were "Alexander Technique" AND music* [all fields], resulting in 97 combinations in PUBMED. Additionally, reference lists were searched, and experts and societies of AT or musicians' medicine contacted to retrieve further publications.

\section{Inclusion and exclusion criteria}

Prospective studies meeting the following criteria were included: Study participants were musicians (children, adults, amateurs, students or professionals, singers and instrumental musicians). Interventions were AT sessions (one-to-one or group lessons) or exercises based on AT principles. The study had a control group, which either received any other or no control intervention. Any outcomes related to music playing, musicians' health or posture were accepted. Randomised controlled trials (RCTs) and controlled trials (CTs) were eligible.

All forms of publications were included, e.g. peerreviewed articles, master's and doctoral theses, conferences presentations etc.

Studies were excluded if they were not related to musicians, AT was mentioned but not investigated, if the article did not report on the results of an interventional study, if it was a study without control group, or a case report or series.

\section{Data collection}

Data were extracted by one author (CB) and verified by a second author (SDK).

For each study, the data extracted were: study design, publication type, study population, experimental intervention(s) and control intervention(s), outcome measures, main results.

\section{Assessment of risk of bias}

The risk of bias was assessed according to Jadad et al. [15], modified as described in [16] with a maximum possible score of 4 for RCTs.

\section{Results}

Of the 237 citations screened, 225 were excluded (Figure 1). Seven citations were classified as "not found", because not even an abstract was available [17-23]. Of the 12 studies included in this review, 3 were peer-reviewed publications, 4 doctoral and 3 master's theses, and 2 appeared in conference proceedings. 5 RCTs, 5 CTs and 2 studies with mixed methods on the effectiveness of AT sessions on music performance, use (and misuse), pain and well-being, posture and performance anxiety are summarised in Table 1. Adverse events of AT sessions were generally not described in the studies.

\section{Randomised controlled trials and mixed methods studies}

Doyle investigated in his $\mathrm{PhD}$ thesis the changes in posture and especially in the head-neck relationship of violinists while playing their instrument [24]. The experimental interventions consisted of short hands-on contact, while one group was asked to think of freeing the sternocleidomastoid muscles, so that the skull moved away from the experimenter's hand (forwards and up) and the other group was asked to think of tightening the muscles, so that the skull moved towards the experimenter's hand (back and down). Photographs were taken before the subjects 


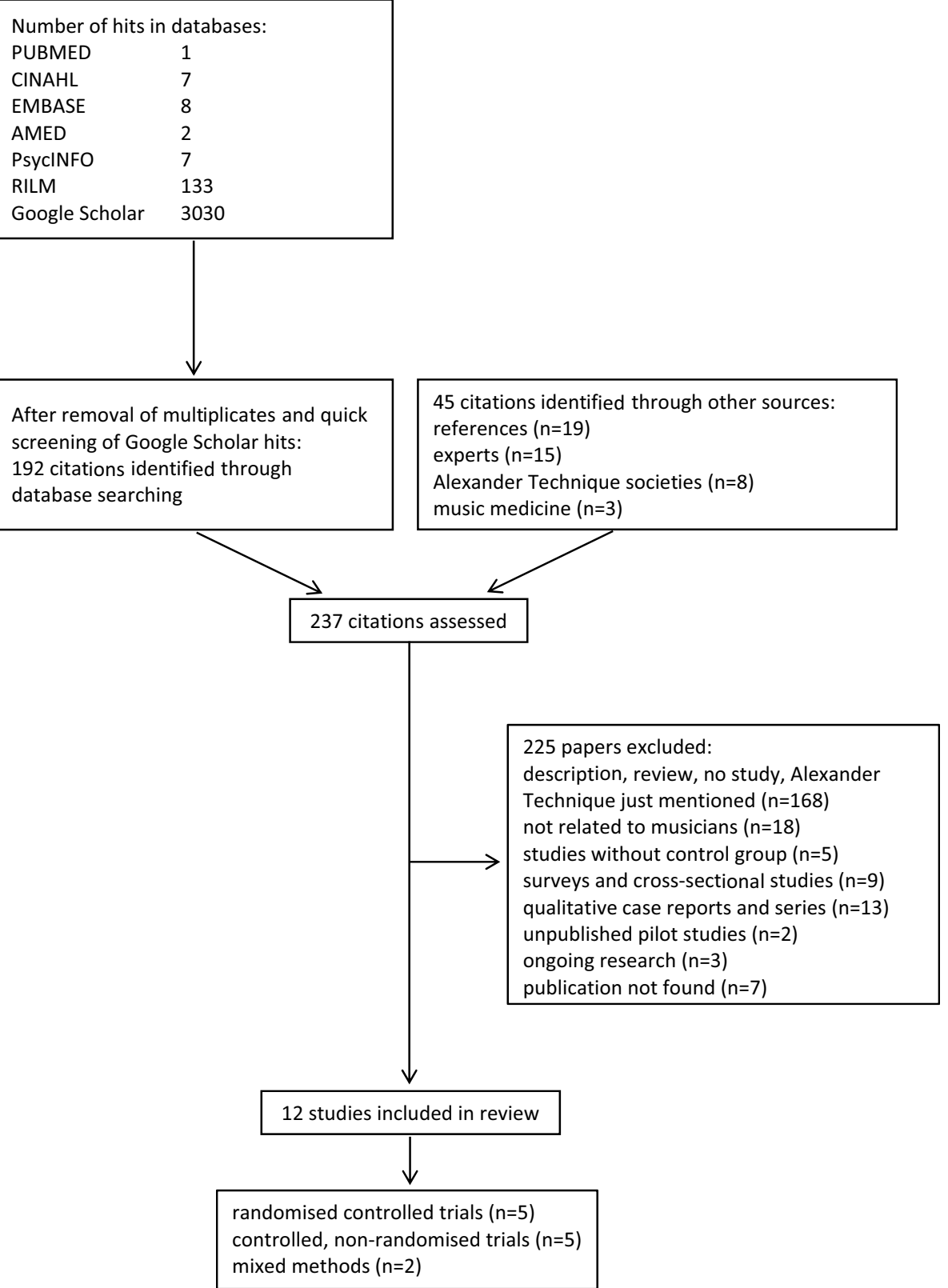

Figure 1 Study selection.

were given their instrument, when holding their instrument and after the short interventions. It was found, that a change in the head-neck relationship occurred when violinists take up their instrument to play, and that a release in tension in the neck muscles was closely associated with postural changes towards the grid vertical. This study did not evaluate the effectiveness of AT sessions, but the immediate effect on posture when subjects were given instructions similar to the initial guidance given by AT teachers. A source of bias in this study was the evaluation of the photographs by the author, who also provided the interventions.
Dennis hypothesised that 20 AT lessons would result in functional improvements in respiratory function and musical performance in young adult wind instrumentalists [25]. When mean difference scores (post - pre) between the AT and the control group were compared, the control group showed better performance in maximal voluntary ventilation than the AT group. No other significant differences in respiratory functions were found. The subjects in the AT group submitted short reports on their experience of the experimental procedure, which suggested a positive effect of the AT lessons. However, no significant differences between AT and control group were shown in the 
Table 1 Selected studies (RCTs and CTs) of effectiveness of AT $^{\mathrm{a}}$

\begin{tabular}{|c|c|c|c|c|c|c|}
\hline $\begin{array}{l}\text { Study, type of } \\
\text { publication }\end{array}$ & Design & Participants & $\begin{array}{l}\text { Experimental } \\
\text { intervention(s) }\end{array}$ & $\begin{array}{l}\text { Control } \\
\text { intervention(s) }\end{array}$ & Outcome measures & Main results \\
\hline \multirow[t]{3}{*}{$\begin{array}{l}\text { Doyle } 1984[24] \\
\text { PhD thesis }\end{array}$} & \multirow[t]{3}{*}{$\mathrm{RCT}$} & 72 & \multirow[t]{3}{*}{$\begin{array}{l}\text { Short hands-on contact } \\
\text { with thought: free neck } \\
\text { muscles before playing }\end{array}$} & \multirow{3}{*}{$\begin{array}{l}\text { Short hands-on } \\
\text { contact with } \\
\text { thought: tighten } \\
\text { neck muscles } \\
\text { before playing }\end{array}$} & Head-neck relationship & $\begin{array}{l}98.6 \% \text { of subjects showed changes } \\
\text { in the head-neck relationship when } \\
\text { taking up their instrument to play. }\end{array}$ \\
\hline & & Violin players & & & \multirow{2}{*}{$\begin{array}{l}\text { (Defined as the angle between a } \\
\text { line going through the sternal } \\
\text { notch and the first dorsal vertebra } \\
\text { and a vertical line going through } \\
\text { the middle of the chair and measured } \\
\text { on photographs) }\end{array}$} & \multirow{2}{*}{$\begin{array}{l}\text { Release in tension in the neck muscles } \\
\text { was closely associated with postural } \\
\text { changes towards the grid vertical in } \\
71.4 \% \text { of subjects }(p<0.001) \text {. When } \\
\text { tightening the neck muscles } 94.6 \% \\
\text { moved in a forward } \\
\text { direction ( } p<0.001 \text { ). }\end{array}$} \\
\hline & & $\begin{array}{l}42 \text { female, } 30 \text { male, } \\
\text { age } 11-19 \text { years } \\
\text { (music schools, school } \\
\text { orchestras) }\end{array}$ & & & & \\
\hline \multirow[t]{3}{*}{$\begin{array}{l}\text { Dennis } 1987 \\
\text { [25], Ed.D. } \\
\text { dissertation }\end{array}$} & \multirow[t]{3}{*}{ RCT } & 13 & AT & None & $\begin{array}{l}\text { Music performance (posture, movement, } \\
\text { breath control, overall performance) } \\
\text { judged by } 6 \text { expert observers from } \\
\text { video-tapes on a 7-point scale }\end{array}$ & \multirow[t]{3}{*}{$\begin{array}{l}\text { Control group performed better in } \\
\text { maximal voluntary ventilation (t-test, } \\
p=0.052 \text { ); no other significant } \\
\text { differences between groups occurred. }\end{array}$} \\
\hline & & $\begin{array}{l}\text { Young adult wind } \\
\text { instrument players }\end{array}$ & \multirow[t]{2}{*}{$\begin{array}{l}20 \text { sessions, } 30 \text { min, over } 4 \\
\text { months, one-to-one }\end{array}$} & & \multirow[t]{2}{*}{$\begin{array}{l}\text { Respiratory function (standard spirometry, } \\
\text { maximal inspiratory and expiratory pressures) }\end{array}$} & \\
\hline & & $\begin{array}{l}8 \text { female, } 5 \text { male, } \\
\text { age } 22-33 \text { years }\end{array}$ & & & & \\
\hline \multirow[t]{4}{*}{$\begin{array}{l}\text { Valentine et al. } \\
1995 \text { [26], peer- } \\
\text { reviewed }\end{array}$} & $\begin{array}{l}\text { mixed } \\
\text { methods: }\end{array}$ & 25 & AT & None & Height, peak flow, heart rate & $\begin{array}{l}\text { AT group showed improvement relative } \\
\text { to control group in musical and technical } \\
\text { quality, heart rate variance, self-rated } \\
\text { anxiety, and positive attitude to } \\
\text { performance (ANOVA, } p<0.05 \text { ). }\end{array}$ \\
\hline & - RCT & Music students & 15 sessions, one-to-one & & $\begin{array}{l}\text { Music performance and degree of misuse } \\
\text { rated by } 4 \text { blinded expert judges from } \\
\text { video-tapes }\end{array}$ & \multirow{3}{*}{$\begin{array}{l}\text { Effects were mostly restricted to } \\
\text { performance in low stress class } \\
\text { situations (with the exception of heart } \\
\text { rate variance). }\end{array}$} \\
\hline & \multirow[t]{2}{*}{-interviews } & \multirow{2}{*}{$\begin{array}{l}21 \text { female, } 4 \text { male, age } \\
19-32 \text { years (music } \\
\text { department of a university) }\end{array}$} & & & Music Performance Anxiety Self-Statement & \\
\hline & & & & & Nowlis mood adjective checklists & \\
\hline \multirow[t]{2}{*}{$\begin{array}{l}\text { Lorenz } 2002 \\
\text { [27], master's } \\
\text { thesis }\end{array}$} & \multirow[t]{2}{*}{$\mathrm{RCT}$} & 22 & $\begin{array}{l}\text { sensory awareness and } \\
\text { body alignment exercises } \\
\text { based on AT }\end{array}$ & None & \multirow{2}{*}{$\begin{array}{l}\text { performance anxiety (degree, symptoms) } \\
\text { and effects of AT on performance anxiety } \\
\text { measured by } 4 \\
\text { questionnaires (designed by author) }\end{array}$} & \multirow[t]{2}{*}{$\begin{array}{l}\text { Inconclusive effect of exercises on } \\
\text { performance anxiety. }\end{array}$} \\
\hline & & $\begin{array}{l}\text { Female choral singers, age } \\
13-16 \text { years (high school) }\end{array}$ & $\begin{array}{l}1 \text { to } 4 \text { min exercises, } 3 \text { to } 4 \\
\text { times weekly, over } 13 \\
\text { weeks, group training }\end{array}$ & & & \\
\hline \multirow[t]{2}{*}{$\begin{array}{l}\text { Egner and } \\
\text { Gruzelier } 2003 \\
\text { [28], peer- } \\
\text { reviewed }\end{array}$} & \multirow[t]{2}{*}{$\mathrm{RCT}$} & 61 & 1. alpha/theta NF & $\begin{array}{l}\text { 4. Physical } \\
\text { exercise }\end{array}$ & $\begin{array}{l}\text { Assessment by } 3 \text { expert judges from video-tape } \\
\text { in random order on 10-point scales adapted } \\
\text { from a standard set of music performance } \\
\text { evaluation criteria (overall quality, perceived } \\
\text { instrumental competence, musicality/musical } \\
\text { understanding } \\
\text { and communication) }\end{array}$ & \multirow[t]{2}{*}{$\begin{array}{l}\text { Significant improvements in music } \\
\text { performance occurred in the alpha/ } \\
\text { theta NF group ( } p<0.01 \text { for } 3 \text { out of } \\
4 \text { criteria; mean improvement rate 12\%), } \\
\text { but no post-training performance } \\
\text { changes in any other group. }\end{array}$} \\
\hline & & music students & 2. beta1 NF & & Spielberger's state-anxiety inventory & \\
\hline
\end{tabular}


Table 1 Selected studies (RCTs and CTs) of effectiveness of AT ${ }^{\mathbf{a}}$ (Continued)

\begin{tabular}{|c|c|c|c|c|c|}
\hline & & & & $\begin{array}{l}\text { 5. Mental skills } \\
\text { training }\end{array}$ & \\
\hline & & 43 female, 18 male, mean & 3. sensorimotor rhythm NF & 6. AT: 15 & \\
\hline & & $\begin{array}{l}\text { age } 23.1 \pm 2.21 \text { years } \\
\text { (college) }\end{array}$ & $\begin{array}{l}10 \text { sessions, } 15 \text { min, over } \\
6-8 \text { weeks }\end{array}$ & $\begin{array}{l}\text { sessions, } 30 \\
\text { min, weekly, } \\
\text { over } 15 \text { weeks, } \\
\text { one-to-one }\end{array}$ & \\
\hline \multirow{2}{*}{$\begin{array}{l}\text { Valentine and } \\
\text { Williamon } 2003 \\
\text { [29], conference } \\
\text { proceedings }\end{array}$} & \multirow[t]{2}{*}{ RCT } & 18 & AT & alpha/theta NF & \multirow{2}{*}{$\begin{array}{l}\text { Assessment of AT use } \mathrm{e}^{\mathrm{b}} \text { by blinded } \\
\text { expert on 7-point scale }\end{array}$} \\
\hline & & Music students (college) & $\begin{array}{l}12 \text { sessions, } 30 \text { min, weekly, } \\
\text { one-to-one }\end{array}$ & $\begin{array}{l}10 \text { sessions, } 15 \\
\text { min, over 6-8 } \\
\text { weeks }\end{array}$ & \\
\hline \multirow[t]{3}{*}{$\begin{array}{l}\text { Mozeiko } 2011 \\
\text { [30], dissertation }\end{array}$} & $\begin{array}{l}\text { mixed } \\
\text { methods: }\end{array}$ & 51 & AT & \multirow[t]{3}{*}{ none } & $\begin{array}{l}\text { Pain, executive skill function, } \\
\text { well-being, } \\
\text { awareness }\end{array}$ \\
\hline & - RCT & $\begin{array}{l}\text { Female violinists and } \\
\text { violists, age } 18-34 \text { years }\end{array}$ & $\begin{array}{l}20 \text { sessions, } 30 \text { min, twice a } \\
\text { week, over } 10 \text { weeks, one- } \\
\text { to-one }\end{array}$ & & $\begin{array}{l}\text { - Questionnaires (quantitative, } \\
\text { questions from author and } \\
\text { previous studies, von Korff scale } \\
\text { for pain, 10-point Likert scales) }\end{array}$ \\
\hline & -Interviews & & $\begin{array}{l}\text { Lie down in semi-supine } \\
\text { position } 10-15 \text { min once } \\
\text { or twice a day }\end{array}$ & & - Interviews (qualitative) \\
\hline \multirow{3}{*}{$\begin{array}{l}\text { Barlow } 1956 \\
\text { [31], peer- } \\
\text { reviewed }\end{array}$} & \multirow[t]{3}{*}{ CT } & 74 & AT ("conditioning") & \multirow{3}{*}{$\begin{array}{l}\text { Verbal } \\
\text { instructions, } \\
\text { manual } \\
\text { adjustment, } \\
\text { exercises }\end{array}$} & \multirow{3}{*}{$\begin{array}{l}\text { Postural faults (according to } \\
\text { author's scoring system) }\end{array}$} \\
\hline & & $\begin{array}{l}44 \text { speech and } 30 \text { music } \\
\text { students }\end{array}$ & & & \\
\hline & & $\begin{array}{l}42 \text { female, } 32 \text { male } \\
\text { (college) }\end{array}$ & & & \\
\hline \multirow{2}{*}{$\begin{array}{l}\text { Armstrong } 1975 \\
\text { [32], master's } \\
\text { thesis }\end{array}$} & \multirow[t]{2}{*}{$C T$} & 8 & AT & \multirow[t]{2}{*}{ none } & $\begin{array}{l}\text { Performance anxiety (author's } \\
\text { questionnaire) }\end{array}$ \\
\hline & & $\begin{array}{l}\text { Piano students (music } \\
\text { department of a university) }\end{array}$ & $\begin{array}{l}\text { 4- } 6 \text { sessions, } 30 \text { to } 45 \mathrm{~min} \text {, } \\
\text { over } 6 \text { weeks, one-to-one }\end{array}$ & & $\begin{array}{l}\text { Qualitative observations } \\
\text { regarding movement }\end{array}$ \\
\hline \multirow{5}{*}{$\begin{array}{l}\text { Nielsen } 1988 \\
\text { [33], conference } \\
\text { proceedings }\end{array}$} & \multirow[t]{5}{*}{$\mathrm{CT}$} & 39 & 1. AT & 2. exercises & heart rate, BP \\
\hline & & $\begin{array}{l}\text { Professional musicians in } \\
\text { orchestra }\end{array}$ & $\begin{array}{l}20 \text { sessions, over } 8 \text { weeks, } \\
\text { one-to-one }\end{array}$ & $\begin{array}{l}7 \mathrm{~km} \text { running } 3 \\
\text { times a week, } \\
\text { over } 8 \text { weeks }\end{array}$ & \multirow[t]{4}{*}{ feedbacks } \\
\hline & & & & 3. beta blocker & \\
\hline & & & & $\begin{array}{l}40 \mathrm{mg} \\
\text { Propranolol, } 1.5 \\
\text { h before concert }\end{array}$ & \\
\hline & & & & 4. placebo tablet & \\
\hline
\end{tabular}

Reduction in pre-performance anxiety

was observed

in all 6 groups $(p<0.05)$

43 female, 18 male, mean $\quad 3$. sensorimotor rhythm NF $\quad$ 6. AT: 15 to NF group in 7 out of 10 measures of AT use ( $p<0.05$, one-tailed values).

Significant changes were found in awareness and executive skill function in AT group compared to control group (MANOVA, $p<0.01$ ).

Convergence of quantitative and

qualitative data showed also

improvement in pain.

In the AT group the number of faults decreased from 9 to 4 in women and from 11 to 5 in men.

In the control group the number of faults increased from 7.5 to 7.9 in women and from 10.6 to 11.7 in men. ${ }^{c}$

AT group experienced less nervousness and stress after training, while there was no change in the control group.

Video-taping revealed less stiffness and increased flexibility in shoulders and neck in the AT group. ${ }^{\circ}$

Exercise group showed

- significant reduction in heart rate (paired t-test, $\mathrm{p}<0.05$ )

- increase in general well-being (responses on qualitative questionnaires).

AT group and beta blocker groups showed 
Hoberg 2008

[35], master's

thesis
23

Beginning singers

18 females, 5 males, age

$18-29$ years (students with

no previous vocal training)

$$
12
$$

flute students with performance anxiety

\section{AT} 10 sessions, 50 min, over 2
weeks, group training

Selected AT principles included in flute lessons (with author)

18 months

$\begin{array}{ll}\text { 2. Progressive } & \text { Tone quality rated by } \\ \text { muscle } & 3 \text { experts } \\ \text { relaxation } & \text { on a 9-point } \\ \begin{array}{l}\text { according to } \\ \text { Jacobson }\end{array} & \text { Likert scale }\end{array}$

Jacobson exercise 10 sessions, 50 min, over 2 weeks, group

training

\section{flute lessons} without AT principles (with

\section{Performance anxiety} (author's questionnaire):

18 months

- degree

- significant reduction in systolic BP $(p<0.02)$

- significant reduction in increases in systolic BP from final rehearsal to concert $(p<0.05)$.

Beta blocker group experienced unwanted side effects.

No significant difference was found after interventions among the 3 groups with respect to change in tone quality.

Group-time interaction effects occurred for 6 of 18 EMG variables (ANOVA, $\mathrm{p}<0.05$ ); no overall pattern indicated differences between the 3 groups.

AT group had decreased performance anxiety.

- symptoms

${ }^{a} A T$ Alexander Technique, $R C T$ randomised controlled trial, $C T$ controlled trial, BP blood pressure, NF neurofeedback, EMG electromyography.

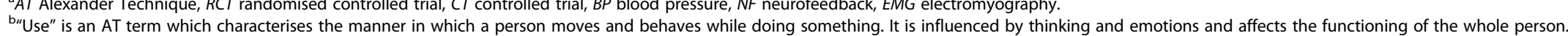
c se is an AT term which characterises the manner in which 
variables rated by the experts judging music performance. The author assumed some degree of subject bias, since blinding of the participants was not possible.

Valentine et al. conducted a mixed methods study with quantitative and qualitative measures to investigate the effects of AT sessions on performance anxiety and music performance [26]. Before and after the course of AT sessions, a variety of measures (e.g. heart rate, music performance, misuse, performance anxiety) were taken in both high (audition, recital) and low stress situations (performance in class). The AT group showed improvements relative to the control group in overall musical and technical quality, heart rate variance, self-rated anxiety and positive attitude to performance. Peak flow as a measure of respiratory function did not significantly improve in the AT group relative to the control. Interviews of the AT group revealed that participants had increased awareness of tension and improved ability to relax. Since these effects were mostly restricted to performance in the low stress situation, it was concluded, that 15 AT lessons were insufficient to develop a level of skill required to apply the technique in high stress situations, or that an enhanced ability to deal with performance anxiety was not the main benefit from AT.

Performance anxiety in 2 high school choirs was investigated by Lorenz [27]. Short sensory awareness and body alignment exercises based on AT were included over 13 weeks in the vocal warm-up of one choir. Degree and symptoms of performance anxiety were assessed in 22 female students by questionnaires pre- and post-exercises, prior to 2 similar school performances. Symptoms of performance anxiety were frequently experienced, and the effect of AT based exercises was inconclusive. In this study, only short exercises based on AT but not AT sessions were provided by the author, who was not a certified AT teacher. The questionnaires to assess performance anxiety were designed by the author and were not validated instruments.

Egner and Gruzelier investigated the effects of 3 neurofeedback (NF) protocols and 3 control interventions (physical exercise, mental skills training, AT) on music performance and performance anxiety [28]. 61 music students were randomly allocated to 1 of 6 training groups. The students performed two musical pieces of their own choice before and after the interventions. The alpha/theta NF group showed significant improvements in music performance, while no significant changes were observed in any of the other groups. A reduction in preperformance anxiety was observed in all 6 groups after training. The main focus in this study lay on NF, while AT was regarded as control intervention. 15 AT sessions may have been again insufficient to evoke an effect on criteria such as e.g. overall quality of music performance or musical understanding. NF and AT training was further compared by Valentine and Williamon regarding AT use [29]. In 7 out of 10 measures of AT use, there were significant interactions between group (AT, NF) and training (before, after). The AT group showed improvements, while the NF group declined. According to the students' feedback AT training was perceived as highly beneficial and satisfactory.

In a mixed methods study using questionnaires, observations and semi-structured interviews, Mozeiko investigated the effects of AT sessions on 4 variables in female violinists and described the experiences of the participants [30]. Outcome measures were awareness, executive skill function, pain and well-being, which were assessed before and after the intervention. The experimental group showed statistically significant improvements in awareness and executive skill function compared to the control group. For pain statistical significance was observed, yet after removing outlying scores to achieve a normal distribution these changes between groups were no longer significant. In contrast to previous studies, participants had more AT sessions and were additionally instructed to lie down in a semi-supine position once or twice a day, which was considered an integral part of learning the AT. All outcome parameters were subjective and assessed by questionnaires.

\section{Controlled trials}

Barlow, a pioneer of AT studies, compared in a study in 1956 postural faults of male and female speech and music students from 2 schools [31]. While the students from the Central School of Speech were given verbal instructions and occasional manual adjustments, the students from the Royal College of Music were trained by AT (described in the article as "a conditioning procedure"). From beginning to end of the training, the number of postural faults defined by the author in the group receiving verbal instructions slightly increased, while in the AT group the number of faults decreased. No statistical analysis was performed, and according to present standards, the study is highly biased.

Armstrong hypothesised that AT sessions would help pianists to cope with stress and nervousness [32]. In the experimental group, less overall stiffness was observed in the second video-taping after AT lessons compared to the one at the beginning. The results of the questionnaires indicated a general decrease in nervousness from pre- to post-treatment performance in all subjects of the AT group whereas the control group considered the nervousness in performance to be as much of a problem as it had been in the first situation. All 4 subjects of the experimental group reported that they wanted to continue with the AT work. The number of participants as well as the number of AT sessions was found to be insufficient to draw reliable conclusions. The study is highly biased, since 
AT sessions were given by the author, who also assessed the video-tapes.

In another controlled trial about performance anxiety by Nielsen [33], 39 musicians were divided into 4 groups (AT, running, beta blocker, placebo tablet). Outcome measures were heart rate and blood pressure (BP). The running group showed a significant reduction in heart rate and an increase in general well-being. The AT and beta blocker groups showed a significant reduction in systolic BP. The placebo group showed no significant changes. Participants in the beta blocker group experienced unwanted side effects such as feeling indifferent or cold, whereas participants in the AT group reported improvements in breathing and surplus energy and in the exercise group an increased well-being. The advantages of this study were objective measurements for stress and the comparison with the application of a beta blocker.

Engelhart tried to determine the impact of preparatory muscle activity (so-called "preparatory set", which is preceding voluntary movement) in singing and to correlate changes in the preparatory set behaviour and improved singing quality [34]. Each participant performed a song before and after training (AT, progressive muscle relaxation according to Jacobson, or standard vocal exercises). These performances were video-taped and rated in random order by 3 expert judges, who rated the tone quality on a 9-point scale. Preparatory muscle activity was determined by surface electromyography (EMG) in 4 participants of each group. No significant differences in change of tone quality were found between groups; therefore, there were no correlations to changes in the preparatory set. It was concluded, that the sample size was too small and the length of the training period was too short to detect significant differences.

Hoberg investigated if performance anxiety could be reduced by implementing principles of AT in flute teaching [35]. One group of 6 students received lessons with a teacher who applied selected principles of AT, the other 6 students had lessons with other teachers, who did not apply AT principles. Comparison of both groups at the end of the study revealed that both groups experienced nervousness, but the participants in the AT group were less nervous than at the previous examination. Comparing the symptoms, the control group had more anxiety symptoms than the AT group. In this study, the participants did not receive AT sessions, but selected AT principles were applied by one of the music teachers who was also the author of this study and not a registered AT teacher. The questionnaires to assess performance anxiety were designed by the author and were not validated instruments. No statistical tests were performed to compare the two groups or pre- and post-results.

\section{Summary of risk of bias}

The risk of bias of the individual studies is summarised in Table 2. Blinding of the participants was impossible due to the nature of the intervention (except in [24]), therefore, a modified Jadad score was used [15,16]. Randomisation procedures were only described in 2 of the RCTs. 6 out of 12 studies had one or several active control groups (e.g. NF, physical exercise, verbal instructions).

Investigators were involved in AT teaching in 5 of the studies, while 5 studies used external teachers and 2 gave no information on this point. Main outcomes were assessed by authors in 3 studies (investigating posture or movement) and by external experts, who were blinded to the assignment to AT or control group of the participants in 5 studies. 3 studies used only questionnaires and 1 only physiological measures.

\section{Discussion}

Posture and movements of a musician influence the sound of his/her instrument or voice. One goal of AT lessons is to create ease and freedom with movement, another that musicians overcome habitual postures that predispose them to injuries or decreased function [36]. The underlying idea of several studies presented here was, that AT lessons would result in an improvement of posture and in turn in music playing.

\section{Summary of evidence}

The most commonly investigated outcomes of AT sessions in clinical trials with musicians were music performance, use, performance anxiety and respiratory function. Music performance was investigated in 3 RCTs and $1 \mathrm{CT}$ and assessed by external experts. Only in 1 RCT the musical quality improved in the AT group while it declined in the control group from pre- to posttraining [26]. In a study comparing NF to AT, alpha/theta NF sessions but not AT sessions improved the music performance [28]. Possible reasons for the inconclusive results may be (i) music performance being a complex process and as such not easy to assess, and (ii) a study duration of 3 to 4 months being too short for the participants to incorporate the skills acquired during AT lessons into their music playing in a way that music performance was observably improved.

Posture, head-neck relationship, movement, effects of AT sessions on use or misuse were investigated in 4 RCTs and 2 CTs. In most RCTs, effects of AT sessions on use ore misuse were inconclusive, yet $1 \mathrm{RCT}$ with defined rating scales reported improved use in the AT group relative to the NF group [29]. One inconclusive RCT reported a very low inter-rater agreement for misuse by 2 AT experts [26], indicating that it may be difficult to assess use or misuse from video-tapes. 
Table 2 Risk of bias in the selected studies

\begin{tabular}{|c|c|c|c|c|c|c|}
\hline Study & $\begin{array}{l}\text { Described as } \\
\text { randomised }\end{array}$ & $\begin{array}{l}\text { Randomisation method } \\
\text { described and appropriate }\end{array}$ & $\begin{array}{l}\text { Assessor unaware of } \\
\text { group allocation } \\
\text { of subjects }\end{array}$ & $\begin{array}{l}\text { Description of } \\
\text { withdrawals } \\
\text { and drop-outs }\end{array}$ & $\begin{array}{l}\text { Score } \\
{[15,16]}\end{array}$ & AT teacher \\
\hline Doyle 1984 [24] & Yes & Yes & No & Yes & 3 & Author \\
\hline Dennis 1987 [25] & Yes & No & Yes & Yes & 3 & $\begin{array}{l}7 \text { certified AT teachers } \\
\text { (not including author) }\end{array}$ \\
\hline $\begin{array}{l}\text { Valentine et al. } 1995 \\
\text { [26] }\end{array}$ & Yes & No & Yes & Yes & 3 & $\begin{array}{l}2 \text { teachers employed } \\
\text { for the study }\end{array}$ \\
\hline Lorenz 2002 [27] & Yes & No & Yes (questionnaires) & Yes & 3 & $\begin{array}{l}\text { Author (without professional } \\
\text { certification in AT) }\end{array}$ \\
\hline $\begin{array}{l}\text { Egner and Gruzelier } \\
2003 \text { [28] }\end{array}$ & Yes & No & Yes & No & 2 & Not described \\
\hline $\begin{array}{l}\text { Valentine and } \\
\text { Williamon } 2003 \text { [29] }\end{array}$ & Yes & No & Yes & No & 2 & Qualified AT teacher \\
\hline Mozeiko 2011 [30] & Yes & Yes & Yes (questionnaires) & Yes & 4 & 9 certified AT teachers \\
\hline Barlow 1956 [31] & No & - & No & No & 0 & Author (AT teacher) \\
\hline Armstrong 1975 [32] & No & - & No & Yes & 1 & $\begin{array}{l}\text { Author (qualified } \\
\text { AT teacher) }\end{array}$ \\
\hline Nielsen 1988 [33] & No & - & Yes & Yes & 2 & Professional AT teacher \\
\hline Engelhart 1989 [34] & No & - & Yes & Yes & 2 & Certified AT teacher \\
\hline Hoberg 2008 [35] & No & - & Yes (questionnaires) & No & 1 & $\begin{array}{l}\text { Author (not a registered } \\
\text { AT teacher) }\end{array}$ \\
\hline
\end{tabular}

Performance anxiety was an outcome in $3 \mathrm{RCTs}$ and 3 CTs and improved by AT in all but $1 \mathrm{RCT}$, in which not one-to-one sessions but only short group exercises bases on AT were provided [27]. While most studies used the Spielberger's state-anxiety inventory or self-designed questionnaires, in $1 \mathrm{CT}$ heart rate and $\mathrm{BP}$ were measured [33]. In studies where AT was compared to active control interventions (e.g. NF or exercise), these other interventions were also effective in reducing performance anxiety. It has been shown, that other interventions such as yoga or physical activity can positively influence performance anxiety $[37,38]$.

No improvements were found in respiratory function in 2 RCTs. In 1 of these wind instrumentalists were investigated [25], who had probably already been training and optimising their breathing [39]. The other study found a non-significant directional effect of improvement in peak flow in the AT compared to the control group [26]. In contrast, a study in healthy volunteers found significant increases in peak expiratory flow, maximal voluntary ventilation, and maximal inspiratory and expiratory mouth pressure after 20 AT lessons [40]. However, compared to the control group, these changes were not significant.

The effects of AT on music playing may be multifaceted, as shown in the various outcome parameters chosen. When subjective measures such as music performance were applied, usually several external experts were involved [28], and sometimes they were trained before [25] or their agreement was determined [26,34].
Participants in the studies included in this review were mostly healthy and young, in contrast to other studies with people suffering from Parkinson's disease [41] or back pain [42], for which AT lessons were effective. Positive results for the effectiveness of AT lessons were obtained for performance anxiety, the only medical condition investigated. None of the studies focused on musicians with pain conditions.

\section{Limitations}

The number of participants was rather low in most studies and ranged from 13 to 72 in RCTs (average 37), from 8 to 74 in CTs (average 31). Statistical tests were not performed in some of the studies. Conference abstracts were limited in word count and did not adequately describe all methods and results.

AT is usually taught in one-to-one sessions, and since it is considered a re-educational method, effects would only be expected after several sessions. In the trials included in this review, one-to-one lessons as well as group training were applied, and training varied from a few minutes to 20 sessions of 30 minutes. A few minutes of group training over several weeks seemed to be insufficient to reduce performance anxiety in female choral singers [27], while 15 one-to-one sessions improved performance anxiety in $2 \mathrm{RCTs}[26,28]$. Although it could be assumed that outcome measure evaluations were performed shortly after the end of the last AT lesson, most studies were not explicit with regard to the timing. 
In this review, amateur musicians, music students and professionals were included. The most often assessed parameter, performance anxiety, seemed to improve by AT sessions in all groups of musicians, but the majority of studies were carried out with music students. The 2 studies with amateurs (children) assessed AT-based exercises rather than AT sessions, that were provided by teachers without professional AT certification [27,35]. Respiratory function was investigated in 2 studies, one with young adult wind instrument players and one with music students from a university, and AT lessons did not improve the outcome in either study. Overall, no comparisons between the groups of musicians and their response to AT lessons can be drawn.

Adverse events (or their absence) were also not described, but AT is considered a low risk method due to the movements that are in range of normal movements. In a back pain trial comparing AT, exercise and massage, none of the 288 patients in the AT groups reported adverse events [42]. Generally, AT is regarded a safe method for which no serious side effects have been reported [43].

This review reported mostly on quantitative data, although 2 studies used a mixed design including interviews. Insufficient reporting of data (without standard deviations or standard errors of the mean) made it impossible to report effect sizes or to conduct a metaanalysis for music performance or performance anxiety.

Additionally to searching databases for studies on AT we contacted experts and societies of AT and musicians' medicine. Nevertheless, we cannot exclude that studies on the effectiveness of AT on musicians' performance or health may have been missed. Seven studies including the respective abstracts were not available [17-23], and thus it remains unclear, whether they had met the inclusion criteria.

The reported outcomes were manifold, ranging from physiological measures (e.g. BP) over self-reported performance anxiety to music performance judged by external experts. The study participants ranged from schoolchildren to professional musicians in an orchestra. Thus, drawing overall conclusions about the effectiveness of AT lessons for musicians was difficult. Nevertheless, this review has relevant implications and its strength lies in presenting the current state of research in this area.

\section{Conclusions}

A variety of study designs and outcome measures has been used to investigate the effectiveness of AT sessions in musicians. Evidence from RCTs and CTs suggests that AT sessions may improve performance anxiety in musicians. Effects on music performance, use and respiratory function yet remain inconclusive. Future trials with well-established study designs, a sufficient number of participants and subjective as well as objective outcomes are warranted to further and more reliably explore the potential of AT as a low risk method in the interest of musicians.

\section{Abbreviations}

AT: Alexander Technique; BP: Blood pressure; CT: Controlled trial; EMG: Electromyography; NF: Neurofeedback; RCT: Randomised controlled trial.

\section{Competing interests}

CB was partly financially supported by the Swiss Association of Teachers of the Alexander Technique (SVLAT). The authors declare that they have no other competing interests.

\section{Authors' contributions}

CB performed the literature search, extracted the data and contributed to writing the manuscript. SDK verified the extracted data and mainly drafted the manuscript. UW designed the study and contributed to and supervised the writing of the manuscript. All authors read and approved the final manuscript.

\section{Acknowledgement}

Financial support to CB of the Swiss Association of Teachers of the Alexander Technique (SVLAT) is gratefully acknowledged. We also thank all authors who provided us with the publications of their studies on AT that were not available online.

Received: 14 July 2013 Accepted: 9 October 2014

Published: 24 October 2014

\section{References}

1. Leaver R, Harris EC, Palmer KT: Musculoskeletal pain in elite professional musicians from British symphony orchestras. Occup Med (Lond) 2011, 61(8):549-555.

2. Ackermann B, Driscoll T, Kenny DT: Musculoskeletal pain and injury in professional orchestral musicians in Australia. Med Probl Perform Art 2012, 27(4):181-187.

3. Zaza C: Playing-related musculoskeletal disorders in musicians: a systematic review of incidence and prevalence. CMAJ 1998, 158(8):1019-1025.

4. Bragge P, Bialocerkowski A, McMeeken J: A systematic review of prevalence and risk factors associated with playing-related musculoskeletal disorders in pianists. Occup Med (Lond) 2006, 56(1):28-38.

5. Wesner RB, Noyes R Jr, Davis TL: The occurrence of performance anxiety among musicians. J Affect Disord 1990, 18(3):177-185.

6. Rietveld $A B$, Leijnse JN: Focal hand dystonia in musicians: a synopsis. Clin Rheumatol 2013, 32(4):481-486.

7. Toppila E, Koskinen H, Pyykkö I: Hearing loss among classical-orchestra musicians. Noise Health 2011, 13(50):45-50.

8. Rodríguez-Lozano FJ, Sáez-Yuguero MR, Bejmejo-Fenoll A: Orofacial problems in musicians: a review of the literature. Med Probl Perform Art 2011, 26(3):150-156

9. Gasenzer ER, Neugebauer EA: Contact allergies in musicians. Dtsch Med Wochenschr 2012, 137(51-52):2715-2721. Article in German.

10. Guptill CA: The lived experience of professional musicians with playing-related injuries: a phenomenological inquiry. Med Probl Perform Art 2011, 26(2):84-95

11. Woodman JP, Moore NR: Evidence for the effectiveness of Alexander technique lessons in medical and health-related conditions: a systematic review. Int J Clin Pract 2012, 66(1):98-112.

12. Bosch AJ: The use of the Alexander Technique in the Improvement of Flute Tone, Master's Dissertation. South Africa: University of Pretoria, Department of Music; 2005.

13. Kaplan I: The Experience of Pianists who have Studied the Alexander Technique: six case Studies, PhD Thesis. New York: New York University; 1994.

14. Moher D, Liberati A, Tetzlaff J, Altman DG: Preferred reporting items for systematic reviews and meta-analyses: the PRISMA statement. PLoS Med 2009, 6(7):e1000097. 
15. Jadad AR, Moore RA, Carroll D, Jenkinson C, Reynolds DJ, Gavaghan DJ, McQuay HJ: Assessing the quality of reports of randomized clinical trials: is blinding necessary? Control Clin Trials 1996, 17(1):1-12.

16. Ernst $\mathrm{E}$, Canter PH: The Alexander Technique: a systematic review of controlled clinical trials. Forsch Komplementärmed Klass Naturheilkd 2003, 10(6):325-329.

17. Calvert C: Investigating the use of the Alexander Technique to Improve Musical Performance, Unpublished Undergraduate Thesis. Salford, UK: University of Salford, School of Computing Science and Engineering; 2006.

18. Fletcher N: Improvement in Musical Performance due to Application of Alexander Technique, Unpublished Master's Thesis. Salford, UK: University of Salford, School of Computing Science and Engineering; 2005.

19. Roberts N: Measurement Science and the Alexander Technique. In 6th International Conference for Alexander Teachers Working in Music Institutions. 20-21 February 2006; Royal Northern College of Music, Manchester. Edited by Williamson A. Mouritz; 2006.

20. Head S: How the Alexander Technique Informs the Teaching of Singing: the Personal Experience of and Analysis by a Singing Teacher, Master's Thesis. British Columbia: University of British Columbia, Department of Curriculum Studies; 1996.

21. Huttlin EJ: A Study of Capacities In Wind Instrumentalists and Vocalists, PhD Thesis. Michigan, USA: Michigan State University; 1982.

22. Hamilton B: The Alexander Technique: A practical application to upper string playing, Doctoral Dissertation. Yale, USA: Yale University; 1986.

23. Richter E: The application of the Alexander Technique to cello playing, Dissertation. USA: Florida State University; 1974.

24. Doyle G: The task of the Violinist: Skill, Stress and the Alexander Technique, PhD thesis. UK: University of Lancaster; 1984

25. Dennis RJ: Musical Performance and Respiratory Function in Wind Instrumentalists, Ed.D. dissertation. New York, NY, USA: Columbia University, Teachers College; 1987

26. Valentine ER, Fitzgerald DFP, Gorton TL, Hudson JA, Symonds ERC: The effect of lessons in the Alexander technique on music performance in high and low stress situations. Psychol Music 1995, 23(2):129-141.

27. Lorenz SR: Performance Anxiety within the Secondary Choral Classroom: Effects of the Alexander Technique on Tension in Performance, Master's Thesis. USA: Michigan State University, Department of Music Education; 2002.

28. Egner T, Gruzelier JH: Ecological validity of neurofeedback: modulation of slow wave EEG enhances musical performance. Neuroreport 2003, 14(9):1221-1224

29. Valentine ER, Williamon A: Alexander Technique and Music Performance: Evidence for Improved "use". In Proceedings of the 5th Triennial ESCOM Conference: 8-13 September 2003; Hanover. Edited by Kopiez R, Lehmann AC, Wolther I, Wolf C. Hanover: Hanover University of Music and Drama; 2003:145-147.

30. Mozeiko KJ: The Effects of Participation in the Alexander Technique on Female Violinists and Violists: a Mixed Methods Study, Dissertation. Boston: Boston University, College of Fine Arts; 2011.

31. Barlow W: Postural deformity. Proc Roy Soc Med 1956, 49(9):670-674.

32. Armstrong J: Effects of the Alexander principle in dealing with stress in music performance, Master's Thesis. USA: Tufts University; 1975.

33. Nielsen M: A study of Stress Amongst Professional Musicians. In Proceedings of the conference of The Alexander Technique: Medical and Physiological Aspects: 29 November 1987; Aalborg. Edited by Stevens C. Aalborg: Folk University; 1988:14-16,

34. Engelhart RJ: An Electromyographic Study of Preparatory set in Singing as Influenced by the Alexander Technique, PhD Thesis. Columbus, Ohio, United States: Ohio State University, School of Music; 1989.

35. Hoberg A: Reducing performance anxiety in woodwind playing through the application of the Alexander Technique principles, Master's Thesis. Pretoria, South Africa: University of Pretoria, Department of Music; 2008.

36. Schlinger M: Feldenkrais method, Alexander technique, and yoga - body awareness therapy in the performing arts. Phys Med Rehabil Clin N Am 2006, 17(4):865-875.

37. Khalsa SB, Butzer B, Shorter SM, Reinhardt KM, Cope S: Yoga reduces performance anxiety in adolescent musicians. Altern Ther Health Med 2013, 19(2):34-45.

38. Rocha SF, Marocolo M, Corrêa EN, Morato GS, da Mota GR: Physical activity helps to control music performance anxiety. Med Probl Perform Art 2014, 29(2):111-112
39. Zuskin E, Mustajbegovic J, Schachter EN, Kern J, Vitale K, Pucarin-Cvetkovic J, Chiarelli A, Milosevic M, Jelinic JD: Respiratory function in wind instrument players. Med Lav 2009, 100(2):133-141.

40. Austin JH, Ausubel P: Enhanced respiratory muscular function in normal adults after lessons in proprioceptive musculoskeletal education without exercises. Chest 1992, 102(2):486-490.

41. Stallibrass C, Sissons P, Chalmers C: Randomized controlled trial of the Alexander technique for idiopathic Parkinson's disease. Clin Rehabil 2002, 16(7):695-708.

42. Little P, Lewith G, Webley F, Evans M, Beattie A, Middleton K, Barnett J, Ballard K, Oxford F, Smith P, Yardley L, Hollinghurst S, Sharp D: Randomised controlled trial of Alexander technique lessons, exercise, and massage (ATEAM) for chronic and recurrent back pain. BMJ 2008, 337:a884.

43. Ulbricht C: Parkinson's disease: an integrative approach. Alternat Complement Ther 2011, 17(3):175-180.

doi:10.1186/1472-6882-14-414

Cite this article as: Klein et al:: The Alexander Technique and musicians: a systematic review of controlled trials. BMC Complementary and Alternative Medicine 2014 14:414.

\section{Submit your next manuscript to BioMed Central and take full advantage of:}

- Convenient online submission

- Thorough peer review

- No space constraints or color figure charges

- Immediate publication on acceptance

- Inclusion in PubMed, CAS, Scopus and Google Scholar

- Research which is freely available for redistribution

Submit your manuscript at www.biomedcentral.com/submit
C Biomed Central 